\title{
PENGARUH REYNOLD NUMBER ( RE ) TERHADAP HEAD LOSSES PADA VARIASI JENIS BELOKAN PIPA ( BERJARI - JARI DAN PATAH )
}

\author{
Mustakim ${ }^{1)}$, Abd. Syakura ${ }^{2)}$ \\ Program Studi Teknik Pendingin dan Tata Udara, Politeknik Tanjungbalai. ${ }^{1)}$ \\ Sei Raja Kel. Sei Raj Kec. Sei Tualang Raso - Tanjungbalai \\ Program Studi Teknik Mesin Politeknik Tanjungbalai. ${ }^{2)}$ \\ Sei Raja Kel. Sei Raj Kec. Sei Tualang Raso - Tanjungbalai \\ Email : Mustakim_ok@yahoo.com
}

\begin{abstract}
ABSTRAK
Penggunaan belokan pipa sangat luas seperti pada sistem transportasi perpipaan karena fleksibilitasnya untuk jaringan dan distribusi. Pemilihan variasi jenis belokan pipa mutlak dibutuhkan untuk mengetahui jenis belokan yang paling kecil nilai head lossesnya terhadap bilanngan reynold nya. Adapun tujuan yang ingin dicapai dalam penelitian ini adalah Mengetahui pengaruh reynold number terhadap head losses pada variasi jenis belokan pipa (Belokan patah dengan diameter $=19,05 \mathrm{~mm}$, Belokan yang berjari-jari dengan $R / D=3,67$ dan $D=19,05$ $\mathrm{mm}$ dan $R / D=1,837$ dan $D=19,05 \mathrm{~mm}$ ) Mengetahui pengaruh reynold number terhadap perbedaan tekanan (pressure drop) pada variasi jenis belokan pipa

( Belokan patah dengan diameter $=19,05 \mathrm{~mm}$, Belokan yang berjari-jari dengan $R / D=3,67$ dan $D=19,05 \mathrm{~mm}$ dan $R / D=1,837$ dan $D=19,05 \mathrm{~mm})$. Variasi nilai reynod number yang digunakan adalah 1293,35 sampai 2586,70

Dari hasil penelitian diperoleh bahwa Reynold number sangat mempengaruhi head losses, semakin tinggi reynold number maka head losses akan semakin meningkat. Pengaruh reynold number pada daerah aliran transisi lebih besar jika dibandingkan pada daerah laminer Nilai head losses yang paling kecil adalah pada jenis belokan dengan R/D 1,837 dan diameter 19,05, sedangkan nilai head losses yang terbesar terdapat pada belokan patah.
\end{abstract}

Kata kunci: Belokan pipa, Head Losses, pressure drop

\section{PENDAHULUAN}

Pada belokan pipa terjadi penurunan tekanan (pressure drop) yang lebih besar daripada pipa lurus untuk panjang yang sama ( Potter,1997 ). Semakin besar $\Delta \mathrm{p}$ atau meningkatnya pressure drop tersebut dapat menyebabkan energi yang dibutuhkan untuk mengalirkan fluida juga meningkat. Penurunan tekanan yang terlalu besar dapat menyebabkan terjadinya kavitasi dan getaran pada instalasi pipa. Terkait dengan fluida, viskositas mempunyai peranan yang penting. Viskositas juga sangat berkaitan dengan bilangan Reynolds. Dengan diketahuinya Re jenis aliran fluida dapat ditentukan laminer atau turbulen. Dalam aliran laminer kerugian tekanan pada aliran sebanding dengan kecepatan fluida, tetapi untuk aliran turbulen kerugian tekanan sebanding dengan kecepatan fluida pangkat 1,7-2,0 ( White, 1986 ). Masalah kerugian tekanan dapat dilihat pula pada persamaan Bernoulli.
Persamaan Bernoulli untuk fluida sesungguhnya menggambarkan keseimbangan energi, dengan mengikutsertakan kerugian-kerugian energi yang terjadi di dalam persamaan tersebut.

Belokan pipa menyebabkan hilangnya energi pada aliran yang cukup besar, hal ini dikarenakan pada belokan terjadi pemisahan aliran dan turbulensi. Kerugian pada belokan semakin meningkat dengan bertambah besarnya sudut belokan. Sudut belokan adalah sudut antara saluran arah masuk aliran terhadap negatif saluran arah keluar aliran. Losses yang terjadi pada belokan disebabkan oleh adanya aliran sekunder (twin eddy/pusaran ganda). Ketika fluida bergerak pada belokan pipa, muncul gaya sentrifugal yang bekerja pada partikel-partikel fluida. Gaya sentrifugal yang terjadi sebanding dengan kuadrat kecepatan fluida. Karena kecepatan fluida yang tidak seragam, semakin besar mendekati pusat dan semakin mengecil mendekati dinding, maka gaya sentrifugal yang bekerja pada tengah arus jauh lebih besar dari 
pada gaya sentrifugal pada lapisan batas. Akibatnya muncul vortex atau swirl yang menyebabkan rotasi fluida dan menghasilkan aliran sekunder. Kualitas pipa dan fitting kecuali di tentukan berdasarkan kualitas fisik berupa tampilan warna, dimensi, sistim koneksi (ulir atau flange) dan lain sebagainya ditentukan pula oleh head losses apabila dialiri fluida. Semakin besar head losses semakin berkurang kualitas pipa dan fitting tersebut. Kualitas fisik dapat mudah dikenali oleh konsumen, namun head losses harus dilakukan penelitian laboratoris (Edi Suhariono, 2008). Pada pendistribusian air sambungan belokan pipa sangat banyak ditemukan baik di industri ataupun di perumahan. Dilihat dari jenis belokannya terdapat dua jenis belokan dalam sambungan pipa, yaitu sambungan belokan patah dan sambungan belokan yang berjari-jari. Dari kedua jenis belokan tersebut yang sering dan paling banyak ditemukan adalah sambungan belokan berjari-jari. Besarnya head losses pada sambungan belokan pipa tersebut dipengaruhi oleh beberapa factor, seperti diameter, debit, viskositas, dan sudut pada sambungan belokan pipa tersebut. Dengan latar belakang tersebut perlu dikaji pengaruh reynold number terhadap energy losses pada beberapa bentuk belokan pipa. Tujuan penelitian adalah Mengetahui pengaruh reynold number terhadap head losses pada variasi jenis belokan pipa (Belokan patah dengan diameter $=19,05 \mathrm{~mm}$, Belokan yang berjari-jari dengan $\mathrm{R} / \mathrm{D}=3,67$ dan $\mathrm{D}=19,05$ $\mathrm{mm}$ dan $\mathrm{R} / \mathrm{D}=1,837$ dan $\mathrm{D}=19,05 \mathrm{~mm}$ ) dan Mendapatkan jenis belokan pipa yang paling kecil head lossesnya.

\section{LANDASAN TEORI}

Penerapan pinsip-prinsip mekanika fluida dapat dijumpai pada bidang industri, transportasi maupun bidang keteknikan lainnya. Namun dalam penggunaannya selalu terjadi kerugian energi. Dengan mengetahui kerugian energi pada suatu sistem yang memanfaatkan fluida mengalir sebagai media, akan menentukan tingkat efisiensi penggunaan energi. Pemakaian variasi sudut belokan menyebabkan perubahan pada head losses dan pressure drop. Semakin besar sudut belokan, nilai head losses dan pressure drop yang dihasilkan semakin besar. Head losses dan pressure drop paling kecil terjadi pada sudut $30^{\circ}$ ( zainuddin, 2012 ). Yudi Sukmono (2009) melakukan penelitian tentang karakteristik aliran dua fase yang melewati elbow $90^{\circ}$ dari arah vertikal menuju horisontal. Rasio $\mathrm{R} / \mathrm{D}=0,6$ dan diameter dalam pipa $=36 \mathrm{~mm}$. Benard (2006) meneliti aliran dua fase melewati belokan $90^{\circ}$ pada pipa vertikal menuju pipa horisontal dengan diameter dalam pipa yang digunakan adalah 0,026 m. Pressure drop pada posisi vertical inlet tangent menunjukkan beberapa perbedaan yang signifikan pada pipa vertikal. Karena adanya elbow yang menyebabkan aliran inlet terhambat sehingga menaikkan tekanan dan jumlah fase liquid pada vertical inlet riser dan perbedaan struktur dari flow regime dibandingkan dengan pipa vertikal lurus tanpa adanya gangguan belokan. Sedangkan horizontal outlet tangent memberikan hasil yang sesuai dengan literatur pada umumnya. Sebuah korelasi empiris untuk pressure drop pada elbow dihasilkan dari persamaan Reynolds number. Tetapi penelitian ini hanya terbatas pada $\mathrm{R} / \mathrm{D}=0,6539$ dan $\mathrm{D}=24 \mathrm{~mm}$ serta batasan Reynolds number pada $\mathrm{ReSG}=$ 2000-30000 dan ReSL= 2800-9800.

\section{METODOLOGI PENELITIAN}

Metode yang digunakan pada penelitian ini adalah eksperimen. Pengukuran head losses menggunakan manometer, sedangkan untuk mengukur penurunan tekanan menggunakan pressure gauge dan diffrensial pressure. Pipa yang digunakan sebagai spesimen uji adalah pipa PVC.

Variasi belokan yang digunakan ada tiga yaitu ( Belokan pipa patah dengan diameter $=19,05 \mathrm{~mm}$, Belokan yang berjari-jari dengan $\mathrm{R} / \mathrm{D}=3,67$ dan $\mathrm{D}=19,05 \mathrm{~mm}$ dan $\mathrm{R} / \mathrm{D}=1,837$ dan $\mathrm{D}=19,05 \mathrm{~mm}$ 
Variasi nilai reynod number yang digunakan adalah 1293,35 sampai 2586,70.

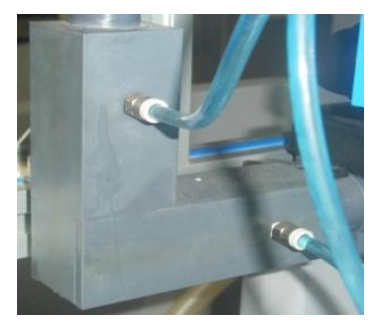

Gambar 1. Belokan pipa patah dengan diameter $=19,05 \mathrm{~mm}$

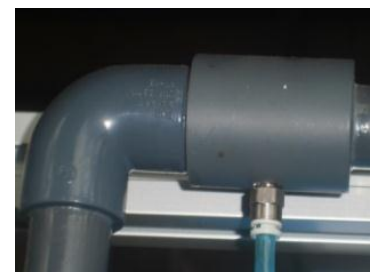

Gambar 2. Belokan yang berjari - jari $\mathrm{R} / \mathrm{D}=$ 1,837 dan $\mathrm{D}=19,05 \mathrm{~mm}$ )

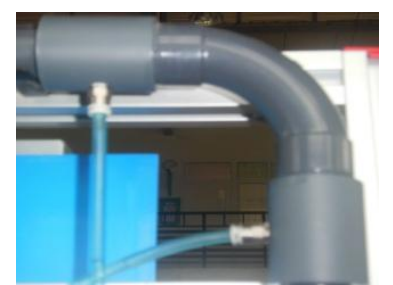

Gambar 3. Belokan yang berjari-jari dengan $\mathrm{R} / \mathrm{D}=3,67$ dan $\mathrm{D}=19,05 \mathrm{~mm}$

\section{HASIL}

\section{Pengaruh Reynold Number ( Re ) Terhadap Head Losses Pada Variasi Jenis Belokan}

A. Pengaruh reynold number terhadap head losses pada belokan patah dengan diameter 3/4"( 19,05 mm )

Head losses adalah head atau kerugian-kerugian dalam aliran pipa yang terdiri atas mayor losses dan minor losses. Kerugian mayor adalah kehilangan tekanan akibat gesekan aliran fluida pada sistem aliran dengan luas penampang tetap atau konstan. Kerugian minor adalah kehilangan tekanan akibat gesekan yang terjadi pada katup-katup, sambungan Tee, sambungan belokan, dan pada luas penampang yang tidak konstan. Pada belokan patah ini diameter pipa yang digunakan adalah 19,05 $\mathrm{mm}$ dengan nilai reynold number 1293,35 sampai 2586,70.

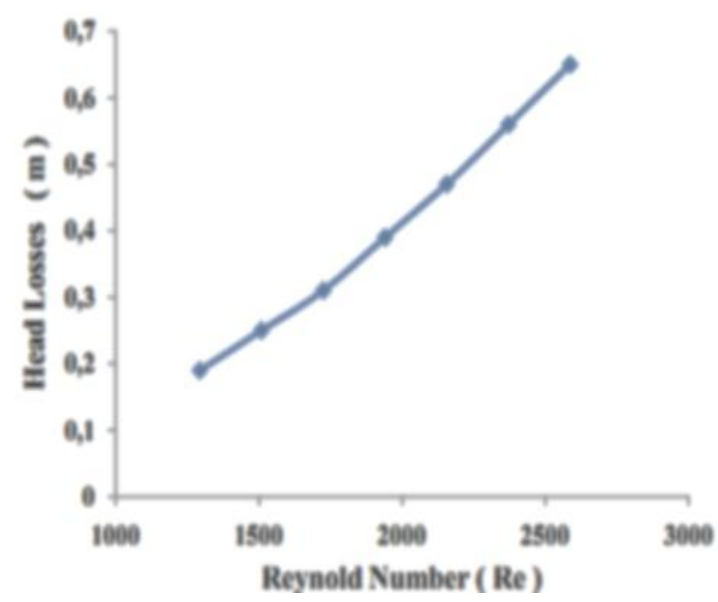

Gambar 4.Grafik pengaruh reynold number terhadap head losses Pada belokan patah

Dari gambar 4 dapat dilihat pengaruh $\mathrm{Re}$ terhadap head losses, dimana semakin meningkat nilai reynold number maka head losses juga akan meningkat, Hal ini disebabkan oleh gesekan yang terjadi antara fluida dengan dinding pipa atau perubahan kecepatan yang dialami oleh fluida.

B. Pengaruh reynold number terhadap head losses pada belokan yang berjari-jari dengan $\mathrm{R} / \mathrm{D}=3,67$ dan $\mathrm{D}=19,05 \mathrm{~mm}$

Pada belokan berjari -jari diameter yang digunakan sama dengan diameter yang dipakai pada belokan patah yaitu 3/4" ( 19,05 $\mathrm{mm}$ ) degan nilai R/D 3,67. Variasi nilai reynod number yang digunakan adalah 1293,35 sampai 2586,70. Dapat dilihat dari gambar 5 pengaruh reynold number terhadap head losses, semakin bertambah nilai reynold number maka head losses juga akan semakin 
meningkat, ini sebabkan pengaruh debit fluida yang mempengaruhi kecepatan rata rata aliran fluida sehingga meningkatkan gesekan yang terjadi antara fluida dengan dinding pipa atau perubahan kecepatan yang dialami oleh fluida. Pada nilai $\operatorname{Re} 1293,35$ head losses nya $0,05 \mathrm{~m}$ sedangkan pada $\mathrm{Re}$ 2586,700807 head losses nya mencapai 0,17 m. Dapat diperhatikan pada daerah aliran transisi kenaikan head losses semakin meningkat bila dibandingkan pada daerah laminer, ini disebabkan karna aliran semakin acak sehingga menyebabkan gesekan fluida dengan dinding pipa semakin besar.

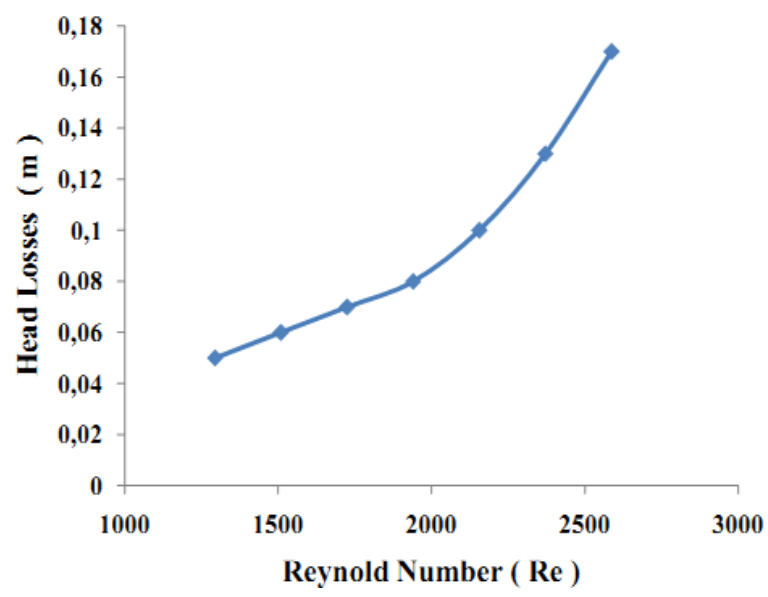

Gambar 5. Grafik pengaruh reynold number terhadap head losses pada belokan yang berjari-jari dengan $\mathrm{R} / \mathrm{D}=3,67$ dan $\mathrm{D}=$ $19,05 \mathrm{~mm}$

C. Pengaruh reynold number terhadap head losses pada belokan yang berjari-jari dengan $\mathrm{R} / \mathrm{D}=1,837$ dan $\mathrm{D}=19,05 \mathrm{~mm}$

Pada gambar 6. dapat dilihat Grafik pengaruh reynold number terhadap head losses pada belokan yang berjari-jari dengan $\mathrm{R} / \mathrm{D}=1,837$ dan $\mathrm{D}=19,05 \mathrm{~mm}$. , Semakin bertambah nilai reynold number maka head losses juga akan semakin meningkat, ini sebabkan pengaruh debit fluida yang mempengaruhi kecepatan rata - rata aliran fluida sehingga meningkatkan gesekan yang terjadi antara fluida dengan dinding pipa atau perubahan kecepatan yang dialami oleh fluida. Pada nilai Re 1293,35 head losses nya $0,15 \mathrm{~m}$ sedangkan pada $\operatorname{Re} 2586,700807$ head losses nya mencapai $0,46 \mathrm{~m}$. Dapat diperhatikan pada daerah aliran transisi kenaikan head losses semakin meningkat bila dibandingkan pada daerah laminer, ini disebabkan karna aliran semakin acak sehingga menyebabkan gesekan fluida dengan dinding pipa semakin besar.

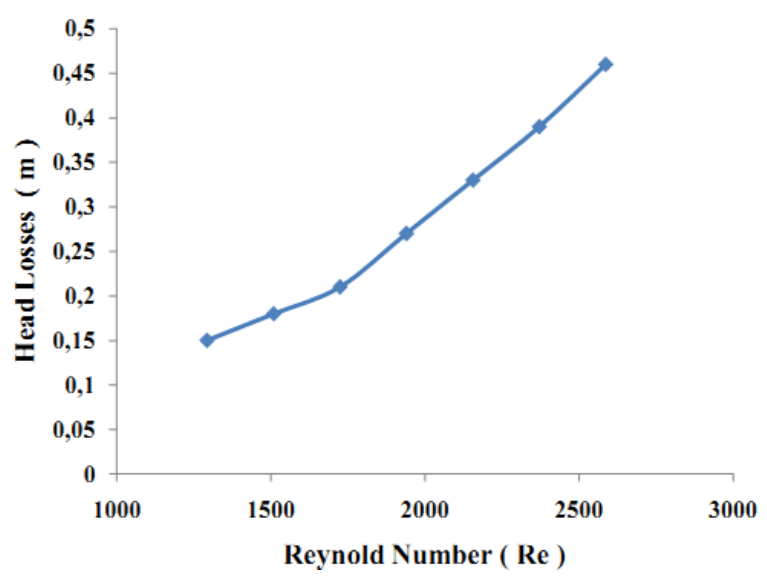

Gambar 6. Grafik pengaruh reynold number terhadap head losses pada belokan yang berjari-jari dengan $\mathrm{R} / \mathrm{D}=1,837$ dan $\mathrm{D}=$ $19,05 \mathrm{~mm}$

D. Pengaruh reynold number terhadap head losses pada variasi jenis belokan

Gambar 7 merupakan perbandingan pengaruh reynold number terhadap variasi jenis belokan yaitu belokan patah dengan diameter 19,05 mm, belokan dengan jari jari R/D 3,67 dan diameter 19,05 mm, belokan dengan jari - jari R/D = 1,837 dan diameter 19,05 $\mathrm{mm}$, dapat dilihat semakin bertambah nilai reynold number maka head losses akan semakin meningkat. Head losses terbesar ditunjukan pada variasi belokan patah, ini disebabkan oleh gesekan yang terjadi antara fluida dengan dinding pipa atau perubahan kecepatan yang dialami oleh 
fluida sangat besar, , pada sudut belokan patah aliran menjadi lebih acak dan terjadi aliran balik. Pada nilai reynold number 1293,35 head losses $0,19 \mathrm{~m}$, sedangkan pada 2586,7 head losses 0,65 m. Head losses terkecil ditunjukan pada variasi belokan dengan jari - jari R/D 3,67 dan diameter 19,05 mm ini dapat terjadi karna hambatan aliran yang diakibatkan gesekan yang terjadi antara fluida dengan dinding pipa cukup kecil. semakin besar nilai R/D maka head losses nya akan semakin menurun.

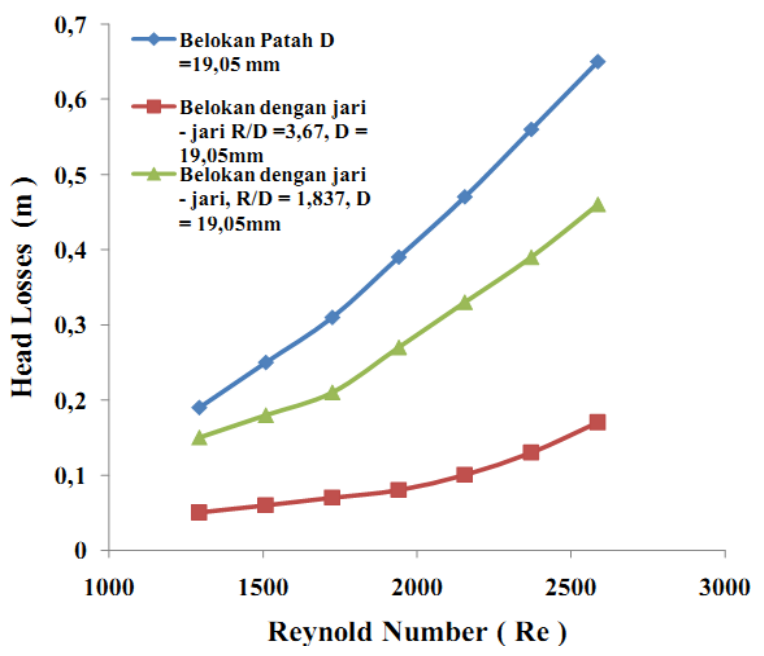

Gambar 7. Grafik perbandingan pengaruh reynold number terhadap Head losses pada variasi jenis belokan.

\section{KESIMPULAN}

Kesimpulan dari penelitian ini dapat dituliskan sebagai berikut:

1. Reynold number sangat mempengaruhi head losses, semakin tinggi reynold number maka head losses akan semakin meningkat.

2. Pengaruh reynold number pada daerah aliran transisi lebih besar jika dibandingkan pada daerah laminer.

3. Nilai head losses yang paling kecil adalah pada jenis belokan dengan R/D 1,837 dan diameter 19,05, sedangkan nilai head losses yang terbesar terdapat pada belokan patah. semakin besar nilai $\mathrm{R} / \mathrm{D}$ maka head losses nya akan semakin menurun.

\section{DAFTAR PUSTAKA}

1. Haruo Tahara, Sularso, 2000. Pompa dan Kompresor. Penerbit PT. Pradnya Pramita, Jakarta.

2. M. White, Frank dan Hariandja, Manahan. 1988. Mekanika Fluida (terjemahan). Erlangga, Jakarta.

3. Potter, Merle, C, and Wiggert, David, C. 1997, Fluid Mechanics; PrenticeHall Inc, New Jersey.

4. Streeter, Victor L. dan Prijono, Arko 1988. Mekanika Fluida (terjemahan). Erlangga, Jakarta.

5. Suhariono, Edi. 2008. Analisa Head Losses dan Koefisien Gesek Pada Pipa. Kalimantan Scientiae.

6. White, Frank. M., 1986, Fluid Mechanics; Mc Graw Hill Book Company, New York.

7. Zainuddin,2012. Analisa Pengaruh Variasi Sudut Sambungan Belokan Terhadap Head Losses Aliran Pipa, Vol. 2 